\title{
Researching, Co-creating and Testing Innovations in Paper Health Information Systems (PHISICC) to Support Health Workers Decision-making: Protocol of a Multi-country, Transdisciplinary, Mixed-methods Research Programme in Three Sub-saharan Countries
}

Xavier Bosch-Capblanch ( $\nabla$ x.bosch@unibas.ch)

Swiss Tropical and Public Health Institute: Schweizerisches Tropen- und Public Health-Institut https://orcid.org/0000-0002-4469-0395

David O'Donnell

Post Normal PLC

\section{Kendall Krause}

Bill \& Melinda Gates Foundation

\section{Christian Auer}

Swiss Tropical and Public Health Institute: Schweizerisches Tropen- und Public Health-Institut

\section{Angela Oyo-lta}

Dept. of Community Medicine, University of Calabar

\section{Mamadou Samba}

Ministère de la Santé et de l'Hygiéne Publique

\section{Graça Matsinhe}

Expanded Program on Immunisation, Ministry of Health

Abdullahi Bulama Garba

National Primary Healthcare Development Agency

Damaris Rodríguez

Sonder Collective

Meike Zuske

Swiss Tropical and Public Health Institute: Schweizerisches Tropen- und Public Health-Institut Anthonia Ngozi Njepuome

Swiss Tropical and Public Health Institute

Sofia Micael Mandjate Lee

Swiss Tropical and Public Health Institute

\section{Amanda Ross}

Swiss Tropical and Public Health Institute: Schweizerisches Tropen- und Public Health-Institut 


\section{Suzanne Gajewski}

Swiss Tropical and Public Health Institute: Schweizerisches Tropen- und Public Health-Institut

\section{Artur Manuel Muloliwa}

Faculty of Health Sciences, Lúrio University

\section{Richard B Yapi}

Centre Suisse de Recherches Scientifiques en Côte d'Ivoire d'Ivoire

\section{David W Brown}

BCGI LLC / pivot-23.5

\section{Research Article}

Keywords: Primary Health Care, Decision-making, Health Information System, Human Centred Design, Sub-Saharan Africa, Côte d'Ivoire, Mozambique, Nigeria

Posted Date: April 28th, 2021

DOI: https://doi.org/10.21203/rs.3.rs-309149/v2

License: (c) (1) This work is licensed under a Creative Commons Attribution 4.0 International License. Read Full License

Version of Record: A version of this preprint was published at Health Research Policy and Systems on August 11th, 2021. See the published version at https://doi.org/10.1186/s12961-021-00768-0. 


\section{Abstract}

\section{Background}

Health Information Systems are crucial to provide data for decision-making and data demands are constantly growing. However, the link between data and decisions is not always rational nor linear and the management of data ends up overloading frontline health workers, who may have to compromise the health care. Despite limited evidence, there is an increasing push for the digitalisation of Health Information Systems, which faces enormous challenges, particularly in remote, rural settings in low- and middle-income countries. Paper-based tools will continue to be used and this warrants efforts to make them more responsive to local needs. Paper Health Information Systems (PHISICC) is a transdisciplinary, multi-country research initiative to create and test innovative paper-based Health Information Systems in three Sub-Saharan African countries.

\section{Methods}

The PHISICC initiative is taking place in remote, rural settings, in Côte d'Ivoire, Mozambique and Nigeria, through partnership with Ministries of Health and research institutions. We began with research syntheses to acquire the most up to date knowledge on Health Information Systems. These were coupled with field work in the three countries to understand the current design, patterns and contexts of use, and health care worker perspectives. Frontline health workers, with designers and researchers, used cocreation methods to produce the new PHISICC tools. This suite of tools is being tested in the three countries. Throughout the project, we have engaged with a wide range of stakeholders and have kept the highest scientific standards to keep it relevant to health policy in each of the three countries.

\section{Discussion}

We have deployed a comprehensive research approach to ensure the robustness and future policy uptake of the finding. Beyond the resulting paper-based tool design innovations, our process itself was innovative. Rather than emphasizing the data management compliance aspects we focused instead on frontline health workers' decision-making; by tackling the whole scope of health care areas in Primary Health Care rather than incremental improvement to existing tools, we developed an entirely new design approach and language for a suite of tools in Primary Health Care. The initiative is being tested in remote, rural areas where the most vulnerable live.

\section{Background}

Better decisions in the clinical, public health or policy domains in health care require good quality evidence on the problems tackled and on their potential solutions and on their implications [ $\left.{ }^{1}\right]$. Decision making is operationalised through Health Information Systems (HIS), which encompass data sources and processes that are meant to inform decisions across the whole health care system [ $\left.{ }^{2}\right]$. HIS include sub-systems such as clinical records, disease surveillance, routine Health Management Information 
Systems (HMIS) and Logistics Management Information Systems, as well as financial data among others [ $\left.{ }^{3}\right]$. However, HMIS can fail to respond to all data demands for decisions and, besides, they may not be used by decision-makers, a topic of debate for decades $\left.{ }^{4}\right]$ which continues today, as exemplified during the COVID-19 pandemic $\left[{ }^{5}, 6\right]$.

Linkages between information and decisions are complex, ill-understood, inconsistent and do not necessarily follow transparent and systematic processes [ [7]. Even with imperfect information reasonable decisions can be (and are) made [ $\left.{ }^{8}\right]$, yet evidence suggests that data and decisions are disconnected [ $\left.{ }^{9}\right]$ and that interventions to improve decision-making are of limited effectiveness, including managerial decisions in subnational areas, such as districts $\left[{ }^{10}\right]$.

Furthermore, accountability requirements at international $\left[{ }^{11}\right]$ and national levels $\left[{ }^{12}\right]$ have multiplied demands for more and better data. For example, the Sustainable Development Goals have a set of 247 indicators across 17 goals $\left[{ }^{13}\right]$. While complaints about data quality have been long reported $\left[{ }^{14}\right]$, substantial efforts have been made to systematize HIS [ $\left.{ }^{15}\right]$, measuring and demanding better data quality $\left[{ }^{16}\right]$ sometimes through the introduction of digital technologies $\left[{ }^{17}\right]$.

Frontline health workers are the primary data collectors at the periphery of the system. They collect health data during the provision of health services and aggregate and transmit them to the higher tiers of the system. They face the challenge of responding to increasing data demands from managers and stakeholders while having to provide good quality care $\left[{ }^{18}\right]$ in their daily routine work. The challenges of increasing demand for quality data have been addressed with some promising digital interventions, however, their design and implementation have shown important caveats [33], particularly in low- and middle-income countries (LMIC), where the need for reliable electrical supply, connectivity, equipment and funding compromise their implementation. Besides, research evidence on the effects of digital solutions remains patchy and inconsistent, even in high-income country settings, where critiques about digitalisation in health care have been raised $\left[{ }^{19}, 20\right]$. Hence, it is very likely that paper tools will remain a substantial, when not the only, data support technology, particularly in remote, rural health facilities (HF) in many countries. Yet, little research exists on how frontline health workers interact with existing paper tools and even less is understood about how these tools can be redesigned to improve data quality and use.

The Bill \& Melinda Gates Foundation (BMGF) recognised the opportunity to invest in research on paperbased tools, issuing a call with the title "Operations Research on Improving Paper-based Information Systems for Child Health" with the aims of designing an innovative paper-based information system for primary health care (PHC) and to test the system's effect on data quality and the provision of care. We describe here the overall PHISICC (Paper-based Health Information System in Comprehensive Care) research programme approach. PHISICC is a multi-year, multi-country, transdisciplinary, mixed-methods research project that aims at producing and testing an innovative paper-based HIS, in three Sub-Saharan African countries. 


\section{Design}

\section{Aims}

The main aims of PHISICC are to create an innovative HIS for PHC and to assess its effects on data use and quality, quality of health care and health care worker perceptions, applied in rural settings in Côte d'Ivoire, Mozambique and Nigeria. The project was approved at the end of 2015, and research activities are planned to mid-2021.

Specifically, we aim at addressing the following research components, organised in six workstreams (WS):

1. Setting up a partnerships between research institutions and the governmental health sector in the three countries, to ensure country ownership, political relevance and scientific excellence (WS1)

2. Synthesising the research literature on the effects of HIS and carrying out a framework synthesis to understand how HIS are portrayed in research (WS2)

3. Characterising the use of HIS in the daily practice of frontline health workers in Côte d'Ivoire, Mozambique and Nigeria (WS3)

4. Designing an innovative paper-based HIS for the three countries (i.e. PHISICC paper-based tools) using a design process employing co-design, human centred design and service design (WS4)

5. Assessing the effects of the PHISICC tools on quality of data, data use and quality of care, through experimental studies in the three countries (WS5)

6. Disseminating the findings and advocating for policy uptake of the new evidence produced (WS6).

\section{Overall research setup and rationale}

The project proposal was developed by a core team composed by the main applicant institution, the design partner and countries' researchers. As the proposal was being drafted, governmental health sector officials from LMIC in Africa and Asia were contacted to ascertain their participation interest for a research project focusing on paper-based HIS. Contacts were made leveraging past and current partnerships of the Swiss Tropical and Public Health Institute (Swiss TPH). We established five criteria to engage with a country: (i) the governmental health sector considered that the paper components of the HIS were going to stay for a long time; (ii) they acknowledge the existence of data quality issues; (iii) they demonstrated that data quality and use was a strategic priority; (iv) they were willing to accept transient changes to the HIS for research purposes; and ( $v$ ) they considered the research relevant to eventually feed into future policy or strategic planning exercises.

The research project pivots around the creation of a new paper-based health information system intervention, using a design process employing co-design, HCD approach and service design (WS4), and testing it using experimental study designs (WS5). It was critical that the design process be informed by 
(i) existing evidence, (ii) real practices and (iii) workers' HCD principles. For these reasons, the design work (WS4) was preceded by the systematic review of the literature (WS2) and the characterisation of the HIS in the countries (WS3). The findings from WS2 and WS3 where synthesised and entered into the cocreation design process (WS4). Equally important was the need to keep the whole research grounded on the real life of the countries' settings and relevant to the strategic priorities of the Ministries of Health. Hence, we established a WS6 to ensure engagement, communication and advocacy with partners since the very conception of the project with concrete activities. The timeline of the project is shown in Figure 1.

\section{Workstream 1: management and inception}

The aims of the inception phase were to set up administrative and managerial procedures, formalise, partnerships and to draft generic protocols for each WS. In each country, we established two main engagements: we signed a Memorandum of Understanding with the relevant department of the governmental health sector; and we entered into contractual arrangements with partner national research institutions. Research partners were selected applying the following criteria: (i) they had, or were interested in having, a portfolio on health systems research; (ii) they had the capacity to manage a longterm project within a wider country partnership; (iii) the PHISICC project was consistent with their own research priorities.

In parallel, we identified international experts that could act as members of a Technical Advisory Group (TAG). The main function of the TAG is to support project partners in project design and implementation, and to monitor progress. We searched and selected experts on HIS, a public health care area (e.g. immunisation), research synthesis and policy, and HCD. TAG members operate on a voluntary basis. A chair was designated by consensus among the six TAG members and two representatives of the funding agency joined the TAG as observers. In the first year of the project, there was one 'global' workshop including the project team with country partners and the TAG.

\section{Workstream 2: global evidence synthesis}

We carried out a systematic literature review to synthesise the evidence on the effects of interventions targeting HIS $\left[{ }^{21}, 22\right]$, following standardized and widely accepted methods $\left[{ }^{23},{ }^{24}\right]$ and reporting practices. To address this 'effectiveness' question, we included experimental and quasi-experimental studies, in any language, carried out in LMIC. We did include in our review studies of any type of intervention targeting HIS, because we could not rule out that studies on, for instance, digital HIS interventions would not have findings or lessons relevant to paper tools. We did not restrict the concept of HIS to the routine HMIS, because we wanted to capture other sources of information that may come into play when making decisions, such as survey results, evaluations or even colloquial evidence.

While the systematic review was meant to provide evidence on the effects of interventions, the TAG raised a concern suggesting that in the systematic review on effectiveness we would miss evidence on systems, 
processes and human experience with the information system. The TAG encouraged the team to carry out another research synthesis to provide additional evidence on the characteristics of the HIS and its use for decision making, as reported in the research literature. Following this recommendation, we carried out a systematic 'framework synthesis' $\left[{ }^{25}, 26\right]$ based on observational, both quantitative and qualitative studies.

\section{Workstream 3: local evidence on health information systems}

We complemented global evidence from gathered in WS2 with local evidence through a characterisation of the HIS in-context of use. These characterisations were carried out in two-week field visits to remote, rural areas in each country, with a team of researchers, HCD experts and governmental health sector officials $\left[{ }^{27}\right]$.

Visits were guided by a protocol and were structured around four main activities: an initial orientation workshop, in-depth interviews with stakeholders, visits to health facilities and restitution workshops. In the initial workshop, partners and stakeholders were updated on project progress and the field visit protocol was shared and adapted. Participatory techniques were used to facilitate engagement and gathering feedback. In-depth interviews addressed the roles of the main stakeholders in identifying and addressing HIS challenges.

Field visits were focused on (i) describing the general features of health facilities and the HIS; (ii) understanding the experience of frontline health workers using the HIS; and (iii) assessing the data quality of selected indicators in the HIS. A novel feature of the PHISICC approach was the application of HCD to understand the frontline health workers' experience with the HIS. The HCD approach involved three to five hours of observations and interviews at each health facility. Activities included 'shadowing health workers to observe their work with patients and tools, and interviewing them to understand their work, their challenges, and the degree to which current HIS tools supported or undermined their ability to do that work. Site visits and interviews were videotaped for detailed review and analysis. Current HIS tools and paper based registers were photographed to create a visual inventory of HIS in context. Informed consent was obtained from health workers and patients prior to recording and individualized patient information was scrubbed.

\section{Workstream 4: Designing an innovative paper-based HIS using a design process}

The design process consisted of co-design and service design methods with a HCD approach. Design has been used as a creative problem-solving approach to translate the findings from WS 2 and 3 into usable, desirable, feasible and effective tools $\left[{ }^{28}\right]$. A HCD approach meant that the lived experiences of the health 
information system users, i.e. health care providers, would be a key aspect of the design decisions (desirability and usability) that needed to be made next to decisions around clinical standards and guidelines (e.g. Integrated Management of Childhood Illness [ $\left.{ }^{29}\right]$ ).

Co-design methods refer to designers' creative activity and people not trained in design, working together in the design development process. Service design methods refer to activities thinking through the HIS' conceptualisation as a service with providers and end-users, using tools such as journey mapping, prototyping, and information design to design consistent and seamless service experiences [ $\left.{ }^{30}\right]$. Cocreation groups were formed to enable the co-design activities, with twelve members from the three partner countries. The co-creation team's role was to co-produce and co-decide on the tools versions, providing their in-country expertise, technical expertise and contextual understanding. The group also contributed to user-testing activities with front-line workers to iterate the tools based on user feedback [31].

The new PHISICC paper-tools include all main health care areas at PHC: antenatal care, delivery, postnatal care, vaccination, sick child, outpatient consultations, HIV and tuberculosis; and the recording, tallying and reporting sub-systems (i.e. recording with register books for individual patient care and tallying and reporting to provide aggregated figures to the higher tiers of the health system). Tools were harmonised across countries, produced in their official languages (English in Nigeria, French in Côte d'Ivoire and Portuguese in Mozambique) and adapted to country specific requirements (e.g. different vaccination schedules). The final versions of the tools were locally produced to supply HF in the intervention arms during the testing period (see WS5).

\section{Workstream 5: evaluation of the intervention using randomised controlled trials}

The PHISICC paper-based tools are being tested in real life situations, using a cluster randomised controlled trial design in the three countries [32,33]. Study areas have been selected based on the availability of remote, rural health facilities, serving vulnerable populations, and being reasonably accessible to carry out research activities. The unit of intervention are the health facilities, which were randomly allocated to the intervention or control arms. In each country, $35 \mathrm{HF}$ were allocated to each arm. In the intervention arm, current HIS paper-based tools were substituted by the new PHISICC tools in order to avoid duplicate recording and reporting. Field work is quality monitored to identify potential problems during the trial implementation.

The outcomes of interest include: (i) health related outcomes (e.g. vaccination coverage rates); (ii) data quality (e.g. consistency between recorded and reported data) and data use outcomes (e.g. documented decisions made based on data); (iii) user related outcomes, both for service providers and patients (e.g. acceptability and usability of new tools); and (iv) resource consumption outcomes (e.g. time spent in reporting data, costs). The effect of the intervention will be estimated by comparing intervention and 
control arms at end-line (for outcomes where only the end-line is available) or differences between baseline and end-line (for outcomes where both baseline and end-line are measured) using regression models taking the structure of the data into account. We have also started to gather qualitative data in order to better understand how the intervention may be working and what are feasible explanations for the observed effects.

\section{Workstream 6: stakeholders engagement, communication and policy advocacy}

WS6 started at the very inception of the project and remains active along the whole project activities (Figure 1). Stakeholders' engagement and countries' ownership are core components of this research to keep it rooted in the reality of the three countries and relevant to the policy contexts. To this end, we have actively adhered to the 11 principles of transboundary research [ $\left.{ }^{34}\right]$, as shown in Table 1.

Communication tools are being leveraged to increase awareness of PHISICC and to allow stakeholders to follow on events. These include activity report $\left.{ }^{35}\right]$, a website (phisicc.org), a twitter account (@phisicc_), a newsletter ('The Tally') and numerous internal memos and updates.

WS6 includes plans to uptake the evidence and lessons learned from PHISICC, which go far beyond the findings of the WS5; including approaches, methods and lessons learned from interactions with frontline health workers.

\section{Status of the study}

In all three countries, WS3 and WS4 have come to an end. Currently the trial (WS5) is on-going in each of the three countries. Data collection has begun in the sense that the baseline data collection was completed in 2020. The end-line data collection has not yet begun.

\section{Discussion}

Research on health systems is challenging due to the complexity of the systems, the limited knowledge of their functioning, the influence of contextual issues as well as the diverse nature of evidence that comes into play, such as evidence on health outcomes, behaviours or finances [1]. Health systems research findings tend to be non-conclusive [ $\left.{ }^{36}\right]$, partially due to these complexities, partially because of the use of less robust research methods. Consequently, we conceived PHISICC to comply with the highest possible standards, ensuring the involvement of research findings users (WS1 and WS6), assessing the existing evidence (WS2 and WS3) $\left[{ }^{37}\right]$ and using innovative (HCD, in WS4) as well as experimental methods (WS5). From the outset researchers and policy makers worked together with a vision to uptake the findings. This will be facilitated if PHISICC findings are robust enough to make it to future systematic reviews $\left[{ }^{38}\right]$ and guidance development $\left[{ }^{39}, 40\right]$. 
We aimed at adding value to the PHISICC initiative through a series of options that we have taken over the life of the project. First, we have focused the whole project on decision-making, rather than on data per se and their technicalities [11]. In doing so, we prioritised decisions made by frontline health workers in their daily routine work, which are decisions on patient care or public health decisions. The paper-based intervention was created to support those decisions.

Second, PHISICC paper-tools intervention has been designed for all health care areas delivered in PHC services (i.e. antenatal care, delivery, vaccination, etc.) and it is not siloed within one or two areas $\left[{ }^{41}, 42\right]$. This is important because, as we already realised, interactions between different health care areas unveil additional challenges and opportunities that remain unseen when research is limited to just one particular area. For example, looking at all health care areas we realised about the extraordinary volume of data that health workers have to handle and that the PHISICC interventions should tackle. We also accounted for the need to connect the PHISICC system with existing digital systems $\left[{ }^{43}\right]$ operating at district level.

Third, the push for digitalisation of HIS worldwide, including in LMIC, is extraordinary and not exempts of challenges $\left[{ }^{44}\right]$. Furthermore, the evidence supporting these efforts is very patchy and generally weak [13]. However, early learnings from PHISICC suggest that there is no real controversy between paper and digital systems and that the future will likely require mixed systems combining the benefits of both paper-based and digital tools. Regardless of the form of a tool, the critical question is the degree to which they facilitate high quality clinical decision-making through human centred principles of usability and design. These principles are applicable to any HIS regardless of its physical form.

Fourth, we have gone on step forward in the intervention design, by using a HCD approach which has put the users of the intervention in the centre of the intervention development. Design is a discipline that applies a specific mind-set and skillset that can be both a complementary and innovative way to design tools and interventions in Global Health $\left[{ }^{45}\right]$. Design can help bring diverse disciplines together in a collaborative manner to unlock new opportunities for positive change in health systems. The result has been a set of tools with a visual language and clinical contents that greatly contrasts with the tabular forms of existing tools, as we have witnessed in the three countries (WS3) and elsewhere $\left[{ }^{46}\right]$ and those targeting higher levels of the system $\left[{ }^{47}\right]$.

Finally, we have also explicitly decided to carry out the research in remote, rural areas. This has indeed introduced additional challenges, mainly related to communication and transport of research teams and research participants, the means to carry out the design field-work, the frequency of trial monitoring visits and the turn-over of staff in rural areas, among others. Yet, the dedication of research teams is making this research viable in those areas where the most vulnerable live.

\section{Abbreviations}

BMGF Bill \& Melinda Gates Foundation 
HCD Human-Centred Design

HIS Health Information Systems

HMIS Health Management Information Systems

PHC Primary Health Care

PHISICC Paper-based Health Information System in Comprehensive Care

Swiss TPH Swiss Tropical and Public Health Institute

TAG Technical Advisory Group

WS Workstream

\section{Declarations}

\section{Ethics approval and consent to participate}

For the fieldwork of WS3, ethical clearance was obtained prior to the fieldwork. The WS5 protocol has been reviewed by the following ethical boards: Comité National Ethique des Sciences de la Vie et de la Santé (CNESVS), reference: 024-19/MSHP/CNESVS-kp (Côte d'Ivoire); Comité Institucional de Bioética para Saúde da Universidade Lúrio, reference: 16.2/Julho/CBISUL/19 (Mozambique); Secretary, Government of Cross River State of Nigeria, Ministry of Health, Calabar Health Research Ethics Committee, reference: CRS/MH/HREC/018/Vol. V1/151 (Nigeria) and Ethikkommission Nordwest- und Zentralschweiz (EKNZ), reference: 2018-01059 (Switzerland).

During the household survey, the informed consent form is presented to the person considered to be the head of the household at the time of the visit. Health workers are also asked to give their consent.

\section{Consent for publication}

Not applicable

\section{Availability of data and materials}

Data will be made available once data collection and data analyses will have been completed. Several publications are planned and the data availability policies of the journals where these manuscripts will be placed will be adhered to.

\section{Competing interests}


The authors declare that they have no competing interests.

\section{Funding}

Bill \& Melinda Gates Foundation - The programme officer has commented on the methods of the study and suggested best ways to adapt it to BMGF grant scope.

\section{Authors' contributions}

XBC and DOD produced the first detailed outline of the project which was later on adapted with contributions from LKK and CAU. Workstreams were further developed and adapted to each country context by AOI and ABG in Nigeria, MS in Côte d'Ivoire and GM in Mozambique. DR lead the whole WS4. MZ led one of the systematic reviews in WS2 and contributed to the co-design process. NN and SM brought in stakeholders (WS6) in Nigeria, and Mozambique, respectively. AR and SG shaped the statistical and trial components of WS5 and substantially contributed to following versions of the project. AM and RBY led WS3 in Mozambique and Côte d'Ivoire, respectively. DWB supported and gave advice all along the project design stages and organised the inputs from the TAG. XBC drafted the first version of the draft, which had contributions from all co-authors.

\section{Acknowledgements}

Members of the PHISICC Technical Advisory Group, chaired by David Brown: Blanche Anya (WHO AFRO), Abdallah Bchir (former Gavi), Marta Gacic-Dobo (WHO HQ), Richard Greffé (AIGA), Pamela Mitula (WHO AFRO), Sandy Oliver (UCL Institute) and Chris Wolf (BMGF).

Research collaborators: Momade Ali, Celso Belo, Bassirou Bonfoh, Lisa Diallo, John Ferreira, Bernard Guessanbi, Caitlin Jarrett, Inza Koné, Felix Malé, Kouadio M'bra and Melanie Wendland.

Thanks to the invaluable institutional support from the Swiss TPH: Prof. Marcel Tanner, Prof. Jürg Utzinger, Prof. Kaspar Wyss.

\section{References}

1. Langlois E, Daniels K, Akl EA. Evidence synthesis for health policy and systems: a methods guide. WHO - AHPSR 2018.

2. World Health Organisation (2010). Chapter 3 "Health information systems". In: Monitoring the building blocks of health systems: a handbook of indicators and their measurement strategies. Geneva: World Health Organization; 2010.

3. Mutale W, Chintu N, Amoroso C, Awoonor-Williams K, Phillips J, Baynes C, et al. Improving health information systems for decision making across five sub-Saharan African countries: Implementation 
strategies from the African Health Initiative. BMC Health Serv Res. 2013;13 Suppl 2(Suppl 2):S9. doi: 10.1186/1472-6963-13-S2-S9. Epub 2013 May 31.

4. Leon N, Balakrishna Y, Hohlfeld A, Odendaal WA, Schmidt BM, Zweigenthal V, et al. Routine Health Information System (RHIS) improvements for strengthened health system management. Cochrane Database Syst Rev. 2020 Aug 13;8:CD012012. doi: 10.1002/14651858.CD012012.pub2. PMID: 32803893.

5. Worrall AP, Connolly MJ, O'Neill A, O'Doherty M, Thornton KP, McNally C, et al. Readability of online COVID-19 health information: a comparison between four English speaking countries. BMC Public Health. 2020 Nov 13;20(1):1635. doi: 10.1186/s12889-020-09710-5. PMID: 33183297; PMCID: PMC7661100.

6. Salomon JA (COVID-19 Statistics, Policy modelling, and Epidemiology Collective). Defining highvalue information for COVID-19 decision-making. Preprint from medRxiv, 08 Apr 2020, DOI: 10.1101/2020.04.06.20052506.

7. Innvaer S, Vist G, Trommald M, Oxman A. Health policy-makers' perceptions of their use of evidence: a systematic review. J Health Serv Res Policy. 2002 Oct;7(4):239-44. doi:

10.1258/135581902320432778.

8. Black BL, Cowens-Alvarado, Gershman S, Weir HK. Using data to motivate action: the need for high quality, an effective presentation, and an action context for decision-making. Cancer Causes Control. 2005 Oct;16 Suppl 1:15-25. doi: 10.1007/s10552-005-0457-5.

9. Chanyalew MA, Yitayal M, Atnafu A, Tilahun B. Routine health information system utilization for evidence-based decision making in Amhara national regional state, northwest Ethiopia: a multi-level analysis. BMC Med Inform Decis Mak. 2021 Jan 26;21(1):28. doi: 10.1186/s12911-021-01400-5. PMID: 33499838; PMCID: PMC7836202.

10. Bhattacharyya S, Issac A, Girase B, Guha M, Schellenberg J, Iqbal Avan B. "There Is No Link Between Resource Allocation and Use of Local Data”: A Qualitative Study of District-Based Health DecisionMaking in West Bengal, India. International Journal of Environmental Research and Public Health. 2020; 17(21):8283. https://doi.org/10.3390/ijerph17218283.

11. Sridhar D, Tamashiro T. Vertical funds in the health sector: lessons for education from the Global Fund and GAVI. 2009. Background paper prepared for the Education for All Global Monitoring Report 2010.

12. WHO, HMN. Framework and standards for country health information systems / Health Metrics Network, World Health Organization - 2nd ed, 2008. ISBN 9789241595940.

13. UN General Assembly. Resolution adopted by the General Assembly on 6 July $2017-71 / 313$. Work of the Statistical Commission pertaining to the 2030 Agenda for Sustainable Development. $10^{\text {th }}$ July 2017.

14. Bosch-Capblanch X, Ronveaux O, Doyle V, Remedios V, Bchir A. Accuracy and quality of immunization information systems in forty-one low income countries. Trop Med Int Health. 2009 Jan;14(1):2-10. doi: 10.1111/j.1365-3156.2008.02181.x. PMID: 19152556. 
15. Health Metrics Network, World Health Organisation (2015). Components of a strong health information system - A guide to the HMN Framework. 2nd edition.

16. Rumisha SF, Lyimo EP, Mremi IR, Tungu PK, Mwingira VS, Mbata D, et al. Data quality of the routine health management information system at the primary healthcare facility and district levels in Tanzania. BMC Med Inform Decis Mak. 2020 Dec 17;20(1):340. doi: 10.1186/s12911-020-01366-w. PMID: 33334323; PMCID: PMC7745510.

17. WHO. Recommendations on digital interventions for health system strengthening. WHO guideline. WHO 2019.

18. Garrib A, Stoops N, McKenzie A, Dlamini L, Govender T, Rohde J, Herbst K. An evaluation of the District Health Information System in rural South Africa. S Afr Med J. 2008 Jul;98(7):549-52.

19. Loder E. Promises, promises. BMJ. 2017 Mar 23;356:j1446. doi: 10.1136/bmj.j1446. PMID: 28336513.

20. Wenger N, Méan M, Castioni J, Marques-Vidal P, Waeber G, Garnier A. Allocation of Internal Medicine Resident Time in a Swiss Hospital: A Time and Motion Study of Day and Evening Shifts. Ann Intern Med. 2017 Apr 18;166(8):579-586. doi: 10.7326/M16-2238. Epub 2017 Jan 31. PMID: 28135724.

21. Bosch-Capblanch X, Zuske M, Christian A, Amadasoun S. Effects of interventions to improve 'health information use systems' on the quality and use of information. National Institute for Heath Research. PROSPERO - https://www.crd.york.ac.uk/prospero/display_record.php?RecordID=35218.

22. Bosch-Capblanch $X$, Zuske $M$, Auer $C$. Making information support systems relevant to decisionmakers: an effectiveness systematic review and a framework synthesis. Abstracts of the 25th Cochrane Colloquium, Edinburgh, UK. Cochrane Database of Systematic Reviews. 2018;(9 Suppl 1). https://doi.org/10.1002/14651858.CD201801.

23. Higgins JPT, Thomas J, Chandler J, Cumpston M, Li T, Page MJ, Welch VA (editors). Cochrane Handbook for Systematic Reviews of Interventions version 6.1 (updated September 2020). Cochrane, 2020. Available from www.training.cochrane.org/handbook.

24. Shea BJ, Reeves BC, Wells G, Thuku M, Hamel C, Moran J, et al. AMSTAR 2: a critical appraisal tool for systematic reviews that include randomised or non-randomised studies of healthcare interventions, or both. BMJ. 2017 Sep 21;358:j4008.

25. Thomas J, O'Mara-Eve A, Harden A, Newman M. Synthesis Methods for Combining and Configuring Textual or Mixed-Methods Data, in: David Gough, Sandy Oliver, James Thomas (Ed.): An Introduction to Systematic Reviews, SAGE, London: 181-210; 2012.

26. Zuske M, Oliver S, Bonfoh B, Njepuome N, Mandjate S, Auer C, et al. 'Real-real world evidence' to understand the use of health information systems for decision making. Abstracts of the Global Evidence Summit, Cape Town, South Africa. Cochrane Database of Systematic Reviews. 2017;(9 Suppl 1). https://doi.org/10.1002/14651858.CD201702.

27. Auer C, O'Donnell D, Bonfoh B, Oyo-Ita A, Njepuome N, Mandjate S, et al. Involving health workers by placing them in the centre: how Human-Centred Design can positively impact research and evidence 
synthesis. Abstracts of the Global Evidence Summit, Cape Town, South Africa. Cochrane Database of Systematic Reviews. 2017;(9 Suppl 1). https://doi.org/10.1002/14651858.CD201702.

28. Mager B. Service Design. In: Erlhoff M, Marshall T, eds. Design Dictionary: Perspectives on Design Terminology. Basel: Birkhäuser; 2007: 354-357.

29. World Health Organization. (2005). Handbook : IMCl integrated management of childhood illness. World Health Organization. https://apps.who.int/iris/handle/10665/42939.

30. Steen M. Tensions in human-centred design, CoDesign. 2011; 7:1, 45-60, DOI: 10.1080/15710882.2011.563314.

31. Sanders EBN \& Stappers PJ (2008) Co-creation and the new landscapes of design, CoDesign. 2008; 4:1, 5-18, DOI: 10.1080/15710880701875068.

32. PACTR - Pan African Clinical Trials Registry - PACTR 201904664660639 https://pactr.samrc.ac.za/

33. Bosch-Capblanch X, Oyo-Ita A, Muloliwa AM, Yapi RB, Auer C, Samba M, et al. Does an Innovative Paper-Based Health Information System (PHISICC) Improve Data Quality and use in Primary Health Care? Protocol of a Multi-Country, Cluster Randomised Controlled trial in Sub-Saharan African Rural Settings., 26 February 2021, PREPRINT (Version 1) available at Research Square [https://doi.org/10.21203/rs.3.rs-266052/v1]

34. Stöckli B, Wiesmann U, Lys JA. A Guide for Transboundary Research Partnerships: 11 Principles, 3rd edition, 2018 (1st edition 2012), Bern, Switzerland. Swiss Commission for Research Partnerships with Developing Countries (KFPE)

35. PHISICC - https://paperbased.info/15422-2/.

36. Ranson MK, Evans DB. Taking health systems research syntheses to the next level: overviews of systematic reviews. Cochrane Database Syst Rev. 2017 Sep 13;9:ED000123. doi: 10.1002/14651858.ED000123. PMID: 28975617.

37. Chalmers I, Bracken MB, Djulbegovic B, Garattini S, Grant J, Gülmezoglu AM, et al. How to increase value and reduce waste when research priorities are set. Lancet. 2014 Jan 11;383(9912):156-65. doi: 10.1016/S0140-6736(13)62229-1. Epub 2014 Jan 8. PMID: 24411644.

38. Langlois EV, Ranson MK, Bärnighausen T, Bosch-Capblanch X, Daniels K, El-Jardali F, et al. Advancing the field of health systems research synthesis. Syst Rev. 2015 Jul 10;4:90. doi: 10.1186/s13643-015-0080-9. PMID: 26159806; PMCID: PMC4498528.

39. Bosch-Capblanch X, Lavis JN, Lewin S, Atun R, Røttingen JA, Dröschel D, et al. Guidance for evidence-informed policies about health systems: rationale for and challenges of guidance development. PLoS Med. 2012;9(3):e1001185. doi: 10.1371/journal.pmed.1001185. Epub 2012 Mar 6. PMID: 22412356; PMCID: PMC3295823.

40. Brown DW, Bosch-Capblanch X, Shimp L. Where Do We Go From Here? Defining an Agenda for Home-Based Records Research and Action Considering the 2018 WHO Guidelines. Glob Health Sci Pract. 2019 Mar 29;7(1):6-11. doi: 10.9745/GHSP-D-18-00431. PMID: 30877139; PMCID: PMC6538131. 
41. Devi BR, Syed-Abdul S, Kumar A, Iqbal U, Nguyen PA, Li YJ, et al. mHealth: An updated systematic review with a focus on HIV/AIDS and tuberculosis long term management using mobile phones. Computer Methods and Programs in Biomedicine. 2015;122(2):257-65.

42. DiFilippo KN, Huang WH, Andrade JE, Chapman-Novakofski K. The use of mobile apps to improve nutrition outcomes: A systematic literature review. Journal of Telemedicine and Telecare. 2015;21(5):243-53.

43. DHIS2 - https://dhis2.org/.

44. Dehnavieh R, Haghdoost A, Khosravi A, Hoseinabadi F, Rahimi H, Poursheikhali A, et al. The District Health Information System (DHIS2): A literature review and meta-synthesis of its strengths and operational challenges based on the experiences of 11 countries. Health Inf Manag. 2019 May;48(2):62-75. doi: 10.1177/1833358318777713. Epub 2018 Jun 13. PMID: 29898604.

45. https://www.designforhealth.org/our-vision-community-of-practice, accessed on 4 March 2021

46. MEASURE Evaluation. Health Management Information System (HMIS) - Participants Handouts and Instruments. 2010.

47. MEASURE Evaluation. Applying User-Centered Design to Data Use Challenges: What We Learned. Chappell Hill (North Carolina), 2017.

\section{Table}


Table 1.

Principles of transboundary research partnership.

\begin{tabular}{|c|c|c|c|}
\hline 1 & $\begin{array}{l}\text { Set the agenda } \\
\text { together }\end{array}$ & $\begin{array}{l}\text { Formal partnership between the Swiss TPH, } \\
\text { National Research Institutions and Ministries } \\
\text { of Health; participation since before proposal } \\
\text { submission. }\end{array}$ & $\begin{array}{l}\text { Agreed protocols for each } \\
\text { WS. }\end{array}$ \\
\hline 2 & $\begin{array}{l}\text { Interact with } \\
\text { stakeholders }\end{array}$ & $\begin{array}{l}\text { Stakeholders' consultations through } \\
\text { workshops and other exchanges. }\end{array}$ & $\begin{array}{l}\text { Stakeholders' analyses; } \\
\text { incorporation of } \\
\text { stakeholder's views. }\end{array}$ \\
\hline 3 & $\begin{array}{l}\text { Clarify } \\
\text { responsibilities }\end{array}$ & $\begin{array}{l}\text { Establishment of generic research } \\
\text { management structure and then adapted in } \\
\text { each country. }\end{array}$ & $\begin{array}{l}\text { Each WS is 'governed' by } \\
\text { specific Terms of Reference, } \\
\text { which are agreed among } \\
\text { partners. }\end{array}$ \\
\hline 4 & $\begin{array}{l}\text { Account to } \\
\text { beneficiaries }\end{array}$ & $\begin{array}{l}\text { Transparent and systematic exchanges } \\
\text { between funding agency, management and } \\
\text { implementation. }\end{array}$ & $\begin{array}{l}\text { Monthly calls with the } \\
\text { BMGF; trial monitoring; } \\
\text { reporting to directorates of } \\
\text { involved institutions. }\end{array}$ \\
\hline 5 & $\begin{array}{l}\text { Promote } \\
\text { mutual } \\
\text { learning }\end{array}$ & $\begin{array}{l}\text { Uncountable forums where issues have been } \\
\text { discussed across the whole team, including } \\
\text { senior and junior researchers and partners. }\end{array}$ & $\begin{array}{l}\text { PHISICC has gradually } \\
\text { incorporated dimensions of } \\
\text { Human Resources and } \\
\text { Quality of Care to the initial } \\
\text { focus of the project on HIS. }\end{array}$ \\
\hline 6 & $\begin{array}{l}\text { Enhance } \\
\text { capacities }\end{array}$ & $\begin{array}{l}\text { Fluent communication about global health } \\
\text { research and funding opportunities. }\end{array}$ & $\begin{array}{l}\text { Collaborations with } \\
\text { partners already extend } \\
\text { beyond PHISICC. }\end{array}$ \\
\hline 7 & $\begin{array}{l}\text { Share data } \\
\text { and networks }\end{array}$ & $\begin{array}{l}\text { Transparent data management mechanisms; } \\
\text { systematic approach to evidence production } \\
\text { and use. }\end{array}$ & $\begin{array}{l}\text { Project newsletter; shared } \\
\text { data-bases; internal memos } \\
\text { in critical stages of the } \\
\text { project. }\end{array}$ \\
\hline 8 & $\begin{array}{l}\text { Disseminate } \\
\text { results }\end{array}$ & $\begin{array}{l}\text { PHISICC dissemination and advocacy plan } \\
\text { produced. }\end{array}$ & $\begin{array}{l}\text { PHISICC preliminary } \\
\text { findings to present in } \\
\text { conferences; manuscripts } \\
\text { sent to peer-reviewed } \\
\text { journals; discussions with } \\
\text { partners for policy uptake. }\end{array}$ \\
\hline 9 & $\begin{array}{l}\text { Pool profits } \\
\text { and merits }\end{array}$ & $\begin{array}{l}\text { Active promotion of partners' visibility in } \\
\text { events and initiatives. }\end{array}$ & $\begin{array}{l}\text { Copyright of PHISICC tools } \\
\text { attributed to the project } \\
\text { partnership. }\end{array}$ \\
\hline 10 & Apply results & Policy uptake plans being produced. & $\begin{array}{l}\text { Conversations on policy } \\
\text { uptake already started. }\end{array}$ \\
\hline 11 & $\begin{array}{l}\text { Secure } \\
\text { outcomes }\end{array}$ & $\begin{array}{l}\text { Post-PHISICC plans being produced in terms } \\
\text { of (i) further applications of HCD and public } \\
\text { health collaborations; (ii) apply lessons } \\
\text { learned to other sub-components of the HIS; } \\
\text { (iii) considerations on scaling-up and } \\
\text { sustainability. }\end{array}$ & No tangible results yet. \\
\hline
\end{tabular}


Figures

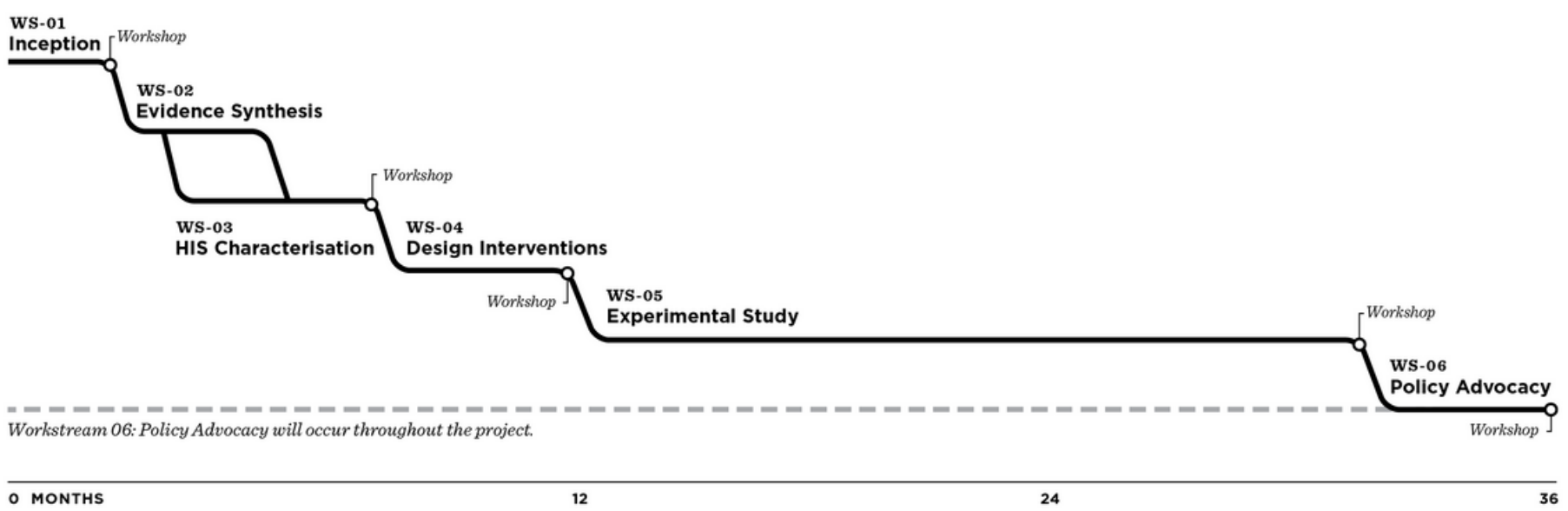

Figure 1

PHISICC programme timeline.

\section{Supplementary Files}

This is a list of supplementary files associated with this preprint. Click to download.

- INV010193Amendment3BMGFallsigned25Nov20.pdf

- PHISICCBMGFGrantAgreement.pdf 